\title{
Exploring pathways to trust: a tribal perspective on data sharing
}

\author{
Rosalina James, PhD¹, Rebecca Tsosie, JD², Puneet Sahota, MD, PhD³, Myra Parker, PhD, JD, \\ Denise Dillard, MA, PhD ${ }^{5}$, Ileen Sylvester ${ }^{5}$, John Lewis ${ }^{6}$, Joseph Klejka, MD', LeeAnna Muzquiz, MD ${ }^{8}$, \\ Polly Olsen, BA ${ }^{9}$, Ron Whitener, JD ${ }^{10}$ and Wylie Burke, MD, PhD'; for the Kiana Group
}

\begin{abstract}
The data-sharing policies of the National Institutes of Health aim to maximize public benefit derived from genetic studies by increasing research efficiency and use of a pooled data resource for future studies. Although broad access to data may lead to benefits for populations underrepresented in genetic studies, such as indigenous groups, tribes have ownership interest in their data. The Northwest-Alaska Pharmacogenetic Research Network, a partnership involving tribal organizations and universities conducting basic and translational pharmacogenetic research, convened a meeting to discuss the collection, management, and secondary use of research data, and of the processes surrounding access to data stored in federal repositories. This article reports the tribal perspectives that emerged from the
\end{abstract}

dialogue and discusses the implications of tribal government sovereign status on research agreements and data-sharing negotiations. There is strong tribal support for efficient research processes that expedite the benefits from collaborative research, but there is also a need for data-sharing procedures that take into account tribal sovereignty and appropriate oversight of research-such as tribally based research review processes and review of draft manuscripts. We also note specific ways in which accountability could be encouraged by the National Institutes of Health as part of the research process.

Genet Med advance online publication 15 May 2014

Key Words: data sharing; ethics; genetics; indigenous; tribal
The National Institutes of Health (NIH) have developed policies to support and promote data sharing, identifying these as "essential for expedited translation of research results into knowledge, products, and procedures to improve human health". ' One component of NIH policy is the expectation that data from certain types of NIH-funded genetic studies will be deposited into a federal data repository, the Database of Genotypes and Phenotypes, for sharing with other researchers. ${ }^{2,3}$ Once data are submitted to the Database of Genotypes and Phenotypes, an NIH Data Access Committee consisting of federal employees reviews researcher applications for data use and determines access based on scientific merit and consistency of proposed research with limitations imposed on the data set (e.g., scope of informed consent). Requests for accessing the Database of Genotypes and Phenotypes largely come from the research community, including academic, governmental, for-profit, and nonprofit institutions. ${ }^{3}$ This approach, and data sharing more generally, has the goal of increasing the efficiency of the research process and promoting public benefit by maximizing the use of a pooled data resource for future studies. It is viewed as a particularly important tool for genomic research, enabling more rapid development of health-related advances. Although the policy promotes broad access to these data, bioethicists have noted unique ethical concerns including adequacy of informed consent to future research, limitations of privacy in modern genetics research, and re-contact of research participants for clinical care or future research. ${ }^{4}$ In addition to the general ethical issues this broad access policy raises, this approach to data sharing raises unique concerns by tribal entities.

The Northwest-Alaska Pharmacogenetic Research Network, an NIH-funded research center involving a partnership among three tribal organizations and three universities to conduct basic and translational pharmacogenetic research, convened a meeting to discuss data sharing and related research issues"Exploring Pathways to Trust"-on 13-15 February 2012. A specific aim of the meeting, addressed in this paper, was to identify knowledge that would be helpful to tribal authorities, researchers, and NIH officials in preparing for discussions about data sharing. Tribal perspectives emerging from the dialogue indicate that the sovereign status of tribal governments and the trust responsibility of the federal government to tribal governments have diverse and unique implications for research agreements and data-sharing negotiations. Consequently,

\footnotetext{
${ }^{1}$ Department of Bioethics and Humanities, University of Washington, Seattle, Washington, USA; ${ }^{2}$ Indian Legal Program, Sandra Day O'Conner College of Law, Arizona State University, Tempe, Arizona, USA; ${ }^{3}$ Department of Psychiatry, Hospital of the University of Pennsylvania, Philadelphia, Pennsylvania, USA; ${ }^{4}$ Department of Psychiatry and Behavioral Sciences, University of Washington, Seattle, Washington, USA; ${ }^{5}$ Southcentral Foundation, Anchorage, Alaska, USA; ${ }^{6}$ Inter Tribal Council of Arizona, Phoenix, Arizona, USA; ${ }^{7}$ Yukon-Kuskokwim Health Corporation, Bethel, Alaska, USA; ${ }^{8}$ Confederated Salish and Kootenai Tribes, Pablo, Montana, USA; ${ }^{9}$ Indigenous Wellness Research Institute, School of Social Work, University of Washington, Seattle, Washington, USA; ${ }^{10}$ Native American Law Center, University of Washington, Seattle, Washington, USA.

Correspondence: Rosalina James (rdjames@u.washington.edu) 
contemporary policy development in this area may require models of intersovereign accord, rather than the traditional models of individual consent and community engagement that are perceived to protect the interests of individuals and vulnerable groups.

\section{MEETING OVERVIEW}

We held a 1.5-day workshop in February 2012 at the Kiana Lodge, Poulsbo, WA, to discuss data sharing and control in the context of university-tribal research partnerships. The meeting was sponsored by the Northwest-Alaska Pharmacogenetic Research Network and the University of Washington Center for Genomics and Healthcare Equality. Meeting attendees included representatives of Northwest-Alaska Pharmacogenetic Research Network tribal partner organizations; indigenous scholars and leaders; university-based researchers; graduate students and postdoctoral fellows from four academic programs, including four indigenous trainees; and senior NIH staff members. The format of the workshop was planned with the help of a professional staff member from the University of Washington Indigenous Wellness Research Institute, who also served as a facilitator for the meeting. The meeting was held on tribal lands, and prior to the meeting, participants attended a dinner of traditional Northwest foods. The group was welcomed by tribal elders who shared stories of personal and historic experiences with environmental, structural, and cultural changes that have occurred since treaty negotiations with the US government and provided blessings for a productive dialogue. The meeting opened with an overview of the Northwest-Alaska Pharmacogenetic Research Network grant as a discovery-oriented pharmacogenomic research project that utilizes community-based participatory research approaches and emphasizes the importance of universitycommunity partnerships to the short- and long-term success of the study. Plenary and small-group discussions encouraged open exchange of diverse views over the course of the meeting. Specific topics included the collection, management, and secondary use of research data and discussion of the processes surrounding access to data stored in federal repositories.

The meeting was not intended to define a universal model for tribal-university data sharing but rather to clarify critical questions and provide space for co-learning among researchers, funders, and tribal representatives. No consensus was sought or expected. Instead, the meeting was designed to identify insights and knowledge that could assist future deliberations, including government-to-government negotiations, aimed at developing acceptable approaches to sharing of tribal data. The tribal perspectives emerging from the meeting are summarized in this paper.

\section{A HISTORY OF MISTRUST}

Tribal participants indicated that contemporary federal policies regarding data sharing are likely to be evaluated by tribal governments within the historical context of federal policies designed to assimilate American Indian and Alaska Native people into the culture of the colonizing United States, ${ }^{5}$ resulting in the loss of tribal lands ${ }^{6}$ and abrogation of tribal sovereignty. ${ }^{7}$ Government actions intended to outlaw tribal practices affected cultural resources, such as language, cultural objects, and religious and healing ceremonies. ${ }^{8}$ These federal policies played a significant role in generating disparities in social determinants of health among American Indian and Alaska Native people. ${ }^{9,10}$ Therefore, current policies intended to promote a "partnership" ethic between tribal governments and researchers must be situated within the legal framework that protects the sovereign rights of tribal governments and remains informed by the lived experiences of indigenous people, who have suffered from past injustices and the contemporary effects of those historic policies. ${ }^{11}$ Prior to addressing questions of how tribal partners might benefit from participation in genomic research, or the implications for data control and ownership on the rights of sovereign nations, personal stories and perspectives were shared to provide all attendees with a baseline understanding of the enduring mistrust of research and federal agencies. Attendees shared examples of both public and private appropriation of tribal lands, sometimes in the name of public health; denigration of tribal customs; and forced choices between poverty and Western acculturation. Collective memories of these experiences continue to have a major impact on the health and socioeconomic status of American Indian and Alaska Native communities. Abuses have also occurred in the research process. Although tribal people have been extensively studied, funding and research processes continue to be controlled by university-based researchers, with little or no input from the community or attention to local health priorities. After completion of a project, researchers often disappear, leaving the community with no information about what the research has accomplished. ${ }^{12}$ In this context, many terms that are common in discussions of data sharing, such as "property," "ownership," and "discovery," are red flags for tribal communities because these terms have historically been used to justify theft of cultural and natural resources, as well as other abuses perpetuated on individual tribal members.

Several recent disputes between biomedical researchers and indigenous groups highlight concerns about data sharing, linking contemporary policy discussions to the historic injustices authorized by federal policymakers. For example, the 2004 lawsuit filed by the Havasupai Tribe against Arizona State University $^{13}$ in connection with a diabetes research project has received extensive national and international attention from indigenous people who are concerned about bioprospectingthe use of indigenous knowledge of plant or animal species for commercial exploitation, such as medicinal drugs. Records developed during the course of litigation document that samples collected from the Havasupai Tribe for diabetes studies were used for other purposes, including investigations of population origin, population migration, and schizophrenia, that were unauthorized, stigmatizing at individual and group levels, and highly offensive to the tribe. ${ }^{14,15}$ The litigation demonstrates that existing federal legal and regulatory protections for human 
subjects fail to shield the cultural interests of Indian nations. Many tribes provided official resolutions and correspondence as a show of support for the Havasupai Tribe, culminating in a 2006 resolution from the National Congress of American Indians backing the Havasupai position and condemning the researchers' actions. ${ }^{16,17}$ A similar case involving the Nuuchah-nulth First Nation in British Columbia, Canada, resulted in the return of blood samples that had been used for studies beyond the research scope approved by the tribe and had been shared with other researchers without the tribe's knowledge. This prompted development of a Research Protocol and Principles guide, the rationale for which states "[researchers] are collectors of information and producers of meaning, which can be used for or against indigenous interests." ${ }^{\prime 8}$ The Nuu-chah-nulth case and other tribal research agreement violations mobilized the Canadian Institutes of Health Research to engage in an extensive consultation process with indigenous communities to develop new guidelines for health researchers. The guidelines call for "re-consent for multiple uses of samples, acknowledgment of intellectual property (IP) rights, and protection of indigenous rights in cultural and sacred knowledge."

It is precisely due to the exploitation of tribal information acquired through research that the need for negotiating the governance and control of data arises. Tribal leaders have deep concerns about giving away rights to aspects of their property or culture and trusting others to do the right thing. ${ }^{19-21}$ As one meeting attendee noted, the language used to discuss The Human Genome Project was "eerily similar" to the terminology used in the 1803 Lewis and Clark expedition: both were framed as "voyages of discovery" and competitive multinational efforts. The Lewis and Clark expedition resulted in US appropriation of tribal lands, whereas tribal health-care and treaty rights remain unfulfilled to this day. Given the intangibility of the "informational commons" that is anticipated to result from data sharing, many people will not perceive a tribal interest in participating in the absence of enforceable methods to ensure transparency and accountability. Trust cannot be assumed and must instead be rebuilt. The challenge is not to ignore the history, but rather to figure out how we can do better.

\section{DATA-SHARING POLICIES FALL UNDER A TRUST RELATIONSHIP WITH THE FEDERAL GOVERNMENT}

From the beginning of the 19th century, US law has considered tribal governments to be "domestic dependent nations," whose rights to governance are ensured by their trust relationship with the federal government. ${ }^{22}$ Federal Indian law principles designate federally recognized tribal governments as separate political sovereigns with inherent authority to govern their territories and their members unless explicitly divested of these rights by Congress. ${ }^{23,24}$ Contemporary tribal governments exercise sovereign authority through their executive, legislative, and judicial functions. ${ }^{1920}$ Tribal governments maintain authority over Indian Country, particularly with respect to trust lands within the reservation, ${ }^{21}$ and they also protect tribal natural resources, such as timber and water, and cultural resources. Tribal members also enjoy distinctive rights under federal and tribal law, and those rights may often be asserted outside of the reservation. In order to protect tribal interests or shield a distinctive group identity from cultural forms of research harm, many tribal governments have issued moratoriums on research. ${ }^{25}$ Therefore, the special legal status of tribal governments requires specific accommodations for tribal rights.

Because tribal sovereignty is federally protected, the US government often must defend tribal rights against the actions of third parties, including state governments or private individuals, who seek to impair those rights. For example, the federal trust restriction on tribal lands and water resources means that those resources may not be alienated without explicit federal consent. Congress holds the "plenary power" to legislate and protect tribal rights, and this has resulted in a voluminous set of laws that regulates the interactions of tribal governments and their members with third parties. To the extent that datasharing policies implicate tribal rights and interests, they will also be regulated by federal law, including restrictions imposed by the trust relationship between Indian nations and the federal government.

\section{HISTORIC POLICIES AND PRACTICES}

Despite the legal recognition afforded to tribal sovereignty, the conduct of the federal government over the past centuries has often been directed toward the destruction of tribal rights and the "assimilation" of tribal members. For example, federal policies authorized Indian children to be removed from their families and sent to distant boarding schools, where they were prevented from speaking their languages or learning about their cultures. ${ }^{26,27}$ Because they were considered "wards" of the federal government, tribal members were also prohibited from practicing their traditional religions and customs. In the 19th century, federal regulations were issued banning tribal ceremonies and customs regarding marriage and inheritance. ${ }^{26}$ In 1924, Congress enacted the Indian Citizenship Act, which naturalized Indians to US citizenship. As US citizens, tribal members were perceived to have Constitutional rights, which made the imposition of the "civilization regulations" problematic. Ultimately, the federal government repudiated the laws and policies of the "civilization" era, although the drive toward assimilation continued until Congress endorsed a policy favoring tribal self-determination in the 1970s. Despite this shift, the legacy of those earlier policies lives on in the collective memory of American Indian and Alaska Native people. For example, one of the Pathways to Trust meeting participants recounted the brutal punishments her grandmother received for speaking her native language in a government-funded boarding school.

Struggles to pass federal and state legislation that addresses subsistence activities also illustrate a complex combination of assimilation and self-determination movements that have deeply impacted the lives of Alaska Native people. ${ }^{27}$ Subsistence through fishing, hunting, and gathering reflects an interconnectedness to the natural world and its resources that is a 
fundamental part of identity, culture, and survival. Many Alaska Native people define subsistence as more than a way of meeting nutritional needs of people living in rural areas-it encompasses essential life teachings that are passed from generation to generation. Congress passed the landmark Alaska Native Claims Settlement Act in 1971 to address the issue of Native land and user rights that interfered with plans for Alaska's oil pipeline and industrial development. Alaska Native Claims Settlement Act resulted in the formation of 12 regional corporations and more than 200 village corporations. These for-profit groups received compensation in the form of partial title of state lands but with implications for their hunting and fishing rights. Today, some Alaska Native people view the Alaska Native Claims Settlement Act as imposing $20^{\text {th }}$-century private enterprise on an ancient subsistence economy, whereas others see it as a vehicle for cultural preservation and economic independence. ${ }^{27}$

\section{TENSIONS IN THE PROTECTION OF CULTURAL HERITAGE}

As the previous discussion indicates, tribal property interests, including IP interests, are heavily implicated in the discussion of data-sharing policies. Because of the federal government's trust relationship with Indian nations, it maintains a separate role in protecting tribal property interests, which makes the resolution of tribal data-sharing policies unlike that of any other group within the United States. For instance, tribal governments have a legal right to protect their cultural heritage, sustained under federal law by their trust relationship with the US government. Even if Congress has not explicitly addressed tribal interests in controlling research data, this interest must be given recognition in relationship to other federal policies that might promote research or authorize the public disclosure of research data. In particular, the Bayh-Dole Act and the Freedom of Information Act have significant implications for researchers and tribal communities. The Bayh-Dole Act, which encourages universities to generate revenue through commercialization and licensing of the products produced by federally funded research, could impact the types of research that academic investigators undertake. The Freedom of Information Act, in its current form, lacks cultural exemptions and has a narrowly construed privacy exemption, which means that it will likely fail to offer sufficient protection for the interests of tribal governments in preventing disclosure of culturally sensitive information. ${ }^{28}$

Federal policymakers must be aware that tribal cultural heritage comprises several discrete elements, such as knowledge, technology, arts, medicine, and genetic resources, and any of these elements might be regarded as having sacred value, which means that public and unauthorized disclosure would harm the tribe..$^{29}$ In addition, aspects of tribal cultural heritage may seem similar to "property," as this concept is construed under AngloAmerican law, but may also have important differences, such as "group ownership," which require different forms of legal protection. In fact, tribal "conceptions of property, ownership, and privacy" may be challenged in cases in which they conflict with the legal and ethical frameworks based on Western philosophies and value systems. ${ }^{29}$

Indigenous people have the right to protect both the tangible and intangible aspects of their cultural heritage, which cannot simply be broken down into these components. For example, some indigenous beliefs consider body parts, blood, tissue, or embryos as part of the "spiritual essence" of an individual. Analysis of genetic material can be perceived as a threat should it be used to question tribal identity, and potentially to "deny a person's or a group's claims to cultural and political rights." 30 Tribes are wary of Western interpretations about group authenticity based on scientific paradigms over their own traditional origin stories and the social, cultural, and political constructs that comprise tribal membership. ${ }^{29,30}$ Tribes seek to protect all of these resources against potential stigmatization, exploitation, or abuse that might harm individual donors, their relatives, or the collective of the group. Similarly, any discrete component of tribal heritage, including the genetic variation revealed in genomic studies, is not separable from its cultural context. Anglo-American forms of protection for "property" and "IP" do not adequately account for tribal cultural forms of ownership, inspiring tribes to enact their own statutes protecting tribal property. The notion of an open "public domain" is a further concern for tribes, such as the Navajo Nation, who claim their tribal culture as IP and actively regulate access to their traditional knowledge. Genetic research tests the boundaries of what is considered cultural forms of ownership. For instance, the University of Hawaii drew strong opposition when researchers announced their intentions to map and patent the Native Hawaiian genome, with the implication that economic and health benefits for Native Hawaiian people would result from the work. Concerns stemmed from the group's experiences with genetic research in which the harms outweighed the benefits of participation, as perceived by the Native Hawaiian families and larger community, including learning the genetic etiology of an incurable rare disorder without appropriate counseling or follow-up with participants. ${ }^{31}$

In this context, researchers have a moral obligation of beneficence beyond a checklist of current human participant requirements set forth in the Nuremberg Code and the Belmont Report. Although institutional review boards are charged with enforcing standards for research involving human participants that focus on the individual, they have little protection for group traditions and beliefs. This interpretation of the beneficence principle requires researchers to minimize harms to individuals but contradicts values held by many indigenous groups that place certain family or community needs and interests before those of the individual. Furthermore, although US law values IP over cultural heritage, this view makes little sense in the indigenous context. It is unclear how intellectual and material property rights should apply, for example, to a ceremony that includes ritual objects as well as songs and other ceremonial practices. ${ }^{29}$ Researchers who have not been grounded in, or are dismissive of, the historical context that shapes values and beliefs held by American Indian and Alaska Native people 
cannot adequately assess the risk related to cultural harms as perceived by these indigenous groups. ${ }^{11,30}$

\section{PARTNERSHIP AND REFRAMING "BENEFIT"}

Despite negative history, some researchers and indigenous communities have developed mutually productive research partnerships. These partnerships often have used communitybased participatory research methods to determine collaborative research priorities and procedures. The community-based participatory research approach values communities as partners in all aspects of the research process and has the potential to reestablish trust and reorganize power relationships. ${ }^{12}$ The Inter-Tribal Council of Arizona offers an instructive example. The council includes the highest elected officials representing 21 tribes in Arizona and administers federal, state, and private grants and contracts in a variety of areas including public health and research. The Inter Tribal Council of Arizona convenes meetings and facilitates active participation of tribal leaders in the "formulation of public policy at all levels." 32 The Inter Tribal Council of Arizona has engaged in a broad array of public health activities and research, with attention to concerns about confidentiality, data sharing, and intellectual and cultural properties. Although community-based participatory research principles provide a useful framework for involving tribes in the research process, the current preference is for tribally based and tribally driven research. The Inter Tribal Council of Arizona has drafted a research services agreement with local universities to help tribes deal with the systematic issues that arise when engaging with researchers. ${ }^{32} \mathrm{~A}$ recurring question when considering research project participation involves defining specifically how the tribes will benefit, a point emphasized at the Pathways to Trust meeting by all of the attending directors of tribal health organizations. Potential benefits identified were both the knowledge resulting from appropriately focused research and the training and employment that may result from research activities.

Although several productive tribal-university research partnerships are in place, few specific examples of tribal benefits from data sharing are currently available. Many times, the benefits of research are poorly defined, indirect, and longterm, whereas possible harms such as stigmatization of small, readily identifiable communities are more immediate. One example of a group working to better understand how benefit from research is perceived is the Southcentral Foundation, an Alaska Native-owned health-care organization in Anchorage. The Southcentral Foundation recently assumed shared ownership, along with the other tribal health corporation members of the Alaska Native Tribal Health Consortium, of the Alaska Area Specimen Bank, a repository of stored samples collected since the 1940s by US-funded research projects in the State. ${ }^{33}$ Working with tribal health organizations, the Southcentral Foundation conducted focus groups with community members and tribal leaders in 14 locations throughout Alaska to explore views of biobanking research. The study revealed that many Alaska Native people were willing to participate in research if it were clearly connected to addressing health concerns or promoting wellness in communities and were also supportive of research where benefits were directed toward future generations with appropriate tribal oversight. ${ }^{33}$

In the context of discussing potential benefits associated with genomic or genetic research, the Pathways to Trust discussion identified an example of data sharing from pharmacogenetics projects that resulted in improved drug dosage tools across ethnic groups. The International Warfarin Consortium consists of research groups from nine different countries that pooled clinical and genetic data from over 5,000 patients receiving treatment with warfarin, a commonly prescribed blood thinner medication. Investigators developed a pharmacogenetic algorithm that could be used to predict the stable therapeutic dose of warfarin for an ethnically and racially diverse cohort of patients, indicating the potential for a genotype-informed application to optimize clinical outcomes for warfarin patients. ${ }^{34}$

One tribal representative at the meeting suggested building reciprocity into the process of data sharing and repositories. When tribes donate samples or data for genomic or genetic studies to develop new medications, is it possible to develop a mechanism whereby tribal members can receive discounts on the downstream products to offset the high cost of newly marketed medications? Although this type of negotiation becomes complicated with stakeholders from the public and private sectors, and long-term prospective planning based on untested discovery and clinical research outcomes is difficult, the suggestion illustrates ways tribal consultation can reframe concepts of benefit and collaborative processes in translational research.

\section{MOVING FORWARD}

On the basis of the trust responsibility of the US federal government to the federally recognized Indian Tribes, President Clinton issued an Executive Order requiring regular and meaningful consultation between the United States and tribal officials in the development of federal policies having tribal implications. As a matter of federal law, ${ }^{35}$ therefore, the federal government must commit to a formal and regular process of consultation with the leaders of federally recognized tribal governments before taking any policy action related to sharing of tribal data, as it must for any action that would potentially jeopardize or impair the integrity of tribal cultural heritage. Consultation with indigenous people is also considered to be fundamental to respecting their human rights under international law. For example, the United Nations Declaration on the Rights of Indigenous Peoples calls for "free and informed consent" by indigenous people before national governments take any action that might impair rights to their cultural heritage. ${ }^{36}$

Through these consultations, tribal governments can express their concerns, which are informed by historical harms associated with past research and policy experiences. Tribal governments seek to ensure the protection of both individual and group rights, ensure responsible research practices, and impose postresearch obligations, where necessary, to ensure compliance with the original agreement. Tribal concepts of ownership, property, and privacy may require continuing control over biological 
materials removed from an individual, rather than treatment as a "biological specimen" to be controlled by the researcher. In this sense, indigenous understandings of human identity and the sacred nature of the body are likely to conflict with the legal and ethical frameworks that are based on Western value systems. ${ }^{11}$ As a result, areas of ethical debate require consultation that is respectful and cognizant of the cross-cultural differences, in particular, the formalized government-to-government consultation required to fulfill federal trust responsibilities to tribes. Participants at the Pathways to Trust meeting were not aware of formal negotiations addressing either sharing of tribal data from federally funded genetic research or submission of tribal data to federal data repositories. However, aggregate data from the Strong Heart study, a longitudinal study of cardiovascular disease and risk factors among American Indians, have been placed in the Database of Genotypes and Phenotypes, with limitations reflecting researcher agreements with tribal partners. ${ }^{37}$ Among the data-use limitations is a bar to the study of individual genotypes or "variables that could be considered as stigmatizing to an individual or group"; this example suggests ways in which tribal concerns might be addressed in negotiations regarding data sharing.

As tribes prepare for such consultations, several resources are now available to support tribal governments and tribally based organizations in regulating research, and negotiating datasharing and ownership agreements. For example, the National Congress of American Indians Policy Research Center has developed a research curriculum for tribal leaders to assist them in managing research and research partnerships ${ }^{38}$; a research regulation toolkit for tribal nations ${ }^{39}$; and a new Web-based resource guide aimed at supporting tribes in their own informed decision making regarding genetics research. ${ }^{40}$ Indigenous groups globally have been involved in creating a growing number of codes of ethics related to IP rights to educate researchers and help funding agencies set expectations for research involving indigenous community members. Many tribes and Alaska Native groups have also established research review processes that include protocols for data ownership and management agreements. ${ }^{41}$

Data sharing may result in benefits for tribal communities, but the risks must be acknowledged and addressed as part of negotiations concerning research policies and partnership agreements. Tribes have ownership interest in their data and traditions, and past experiences with genetic research have made tribes cautious of broad data-sharing agreements. There is strong support for efficient research processes that expedite the time required to generate benefits from collaborative research despite serious concerns about the potential for harm, but as noted by NIH officials, moving forward "depends on the scientific community's ability to maintain the public's trust." 42 Developing data-sharing strategies and protocol may be an appropriate step to achieve this objective, but procedures to do so must take into account tribal sovereignty and the need for accountability. Tribes may use a range of mechanisms to ensure appropriate oversight of research-e.g., research review committees, tribally based institutional review boards, and review of draft manuscripts. The key elements are transparency of the data-sharing obligations and options and the opportunity for tribal authorities to review and approve research involving tribal samples or data.

The trend from study-specific to broad informed consent of individuals for participation in genomic research focuses tribal leadership on the interests and risks of submitting data into government-controlled repositories, including a consideration of legal or other mechanisms to preserve cultural heritage and protect against tribal level harm..$^{20,28}$ In this context, questions raised in the Pathways to Trust meeting discussions included: Can information in the public domain have restrictions on how it may be used in patents or for profit? Can genomic information from geographically isolated indigenous groups be truly de-identified if genetic variation distinguishes them from other populations? Can new models for tribal representation on the Data Access Committees for federal repositories be explored to develop conditions for secondary data uses, including evaluation of the appropriateness of studies and their potential for benefit or harm to indigenous sources?

There are several specific ways in which accountability could be encouraged by the NIH as part of the research process. The NIH could develop mechanisms focused on consultation between researchers, research institutes, and the tribal leadership and community to negotiate data-sharing plans in the context of the study period or through stand-alone planning grants. The group suggested encouraging the NIH and other government funders to include dollars designated for consultation with tribes prior to and throughout the research period. Grant proposals could also require a dissemination plan that specifies how researchers will provide information back to the community during the project period and after completion of the research, which could take the form of resources for community meetings and travel to public venues for tribal representatives and researchers. The group noted that the step of returning to communities could be combined with a research partnership evaluation component that would benefit the NIH by identifying the elements of collaboration that strengthen trust and facilitate respectful negotiation. The group also felt that tribes should have an opportunity to give input related to, and be involved in, the review process for any secondary research uses of tribal data. This could entail tribal representation on review committees, government-togovernment consultation process, or both. Other suggestions included capacity-building requirements for grant proposals, requiring tribal approval as part of the NIH grant approval process, and revisiting the definitions of tribal benefit and dissemination to ensure that there was common agreement about the meaning of these terms. In the contemporary era, federal policies favoring scientific discovery and innovations in biotechnology must be moderated by respect for tribal sovereignty. In any tribal-university partnership, it will be necessary to establish a relationship of trust in which tribal laws and cultural interests are given deference and in which an ethic of respectful negotiation is used to secure the rights of the tribe and the interests of the research community in promoting forms of knowledge that are truly of benefit to all. 


\section{ACKNOWLEDGMENTS}

The authors thank all of the participants of the Pathways to Trust meeting. This work was supported by the Northwest-Alaska Pharmacogenomics Research Network (NIGMS U01GM092676) and the Center for Genomics and Healthcare Equality (NHGRI P50HG3374).

The content is solely the responsibility of the authors and does not necessarily represent the official views of the National Institutes of Health or the authors' affiliated institutions.

The Kiana Group includes meeting attendees Melody Allen, Vence Bonham, Bert Boyer, Wylie Burke, Sheila Caldwell, Katrina Claw, Denise Dillard, Elizabeth Dorfman, Richard Fabsitz, Joe Finley, Nanibaa' Garrison, Scarlett Hopkins, Rosalina James, Barbara Kavanaugh, Joseph Klejka, John Lewis, Rochelle Long, Michelle Montgomery, LeeAnna Muzquiz, James Nicori, Polly Olsen, Myra Parker, Mark Pershouse, Laura Rodriguez, Puneet Sahota, Robin Sigo, Helene Starks, lleen Sylvester, Lisa Rey Thomas, Timothy Thomas, Kenneth Thummel, Susan Brown Trinidad, Rebecca Tsosie, Joseph Yracheta, Kathleen McGlone West, Ron Whitener, and Erica Woodahl.

\section{DISCLOSURE}

The authors declare no conflict of interest.

\section{REFERENCES}

1. Data Sharing Policy. National Institutes of Health website. Published 26 February 2003. http://grants.nih.gov/grants/policy/data_sharing/. Accessed 2 April 2014

2. Policy for sharing of data obtained in $\mathrm{NIH}$ supported or conducted genomewide association studies (GWAS). National Institutes of Health website. Published 28 August 2007. http://grants. nih.gov/grants/guide/notice-files/NOTOD-07-088.html. Accessed 2 April 2014.

3. Walker L, Starks $H$, West KM, Fullerton SM. dbGaP data access requests: a call for greater transparency. Sci Trans/ Med 2011;3:113cm34.

4. Peppercorn J, Shapira I, Deshields T, et al. Ethical aspects of participation in the database of genotypes and phenotypes of the National Center for Biotechnology Information: the Cancer and Leukemia Group B Experience. Cancer 2012;118:5060-5068.

5. Hoxie FF. A Final Promise: The Campaign to Assimilate the Indians, 1880-1920. University of Nebraska Press: Lincoln, NE, 1984.

6. Otis DS. The Dawes Act and the Allotment of Indian Lands. University of Oklahoma Press: Norman, OK, 1973.

7. Joseph W. Canons of conquest: the supreme court's attack on tribal sovereignty. New Eng Law Rev. 2003;37:641.

8. Tsosie R. Reclaiming native stories: an essay on cultural appropriation and cultural rights. Ariz State Law J 2002;34:299.

9. Goodkind JR, Hess JM, Gorman B, Parker DP. "We're still in a struggle": Diné resilience, survival, historical trauma, and healing. Qual Health Res 2012;22:1019-1036.

10. Sotero M. A conceptual model of historical trauma: implications for public health practice and research. J Health Dispar Res Pract 2006;1:93-108.

11. Reardon J, TallBear K. "Your DNA is our history": genomics, anthropology, and the construction of whiteness as property. Curr Anthropol 2012;53:S233-S245.

12. Wallerstein N, Duran B. Community-based participatory research contributions to intervention research: the intersection of science and practice to improve health equity. Am J Public Health 2010;100(suppl 1):S40-S46.

13. Havasupai Tribe $v$ Arizona Board of Regents, 204 P3d 1063, (Ariz App Div 1 2008).

14. Dalton R. When two tribes go to war. Nature 2004;430:500-502.

15. After Havasupai litigation, Native Americans wary of genetic research. Am J Med Genet 2010;152A:fm ix.

16. National Congress of American Indians. Resolution \#SAC-06-019, Supporting the Havasupai Indian Tribe in their claim against the Arizona Board of Regents regarding the unauthorized use of blood samples and research (2006). http://www.ncai.org/resources/resolutions/supporting-the-havasupai-indiantribe-in-their-claim-against-the-arizona-board-of-regents-regarding-theunauthorized-use-of-blood-samples-and-research. Accessed 2 April 2014.

17. National Congress of American Indians. Resolution \#PSP-09-054, Reaffirmation of support for the Havasupai Tribe in its lawsuit against the Arizona Board of Regents (2008). http://files.ncai.org/resolutions/PSP-09-054_final.pdf. Accessed 2 April 2014.

18. Nuu-chah-nulth Tribal Council Research Ethics Committee. Protocols and principles for conducting research in a Nuu-chah-nulth context (2008). http://www. fnehin.ca/uploads/docs/NTC_Research_Protocol.pdf. Accessed 2 April 2014.

19. Jacobs B, Roffenbender J, Collmann J, et al. Bridging the divide between genomic science and indigenous peoples. J Law Med Ethics 2010;38:684-696.

20. Harding A, Harper B, Stone $D$, et al. Conducting research with tribal communities: sovereignty, ethics, and data-sharing issues. Environ Health Perspect 2012;120:6-10.

21. Coffey W, Tsosie R. Rethinking the tribal sovereignty doctrine: cultural sovereignty and the collective future of Indian nations. Stanford Law Pol Rev 2001;12:191-221.

22. Cherokee Nation v. Georgia, 30 US (5 Pet) 1 (1831); Worcester v. Georgia, 31 US (6 Pet) 515 (1832).

23. 18 United States Code, $\$ 1151$ (a) Indian country defined (1949). See Felix Cohen, Cohen's Handbook of Federal Indian Law §3.04 (2005).

24. United States v Wheeler, 435 US 313, 323-324 (1978).

25. Brugge $D$, Missaghian M. Protecting the Navajo People through tribal regulation of research. Sci Eng Ethics 2006;12:491-507.

26. Goldberg CE, Tsosie R, Washburn KK, and Washburn, ER. American Indian Law: Native Nations and the Federal System, 6th edn. Matthew Bender \& Company: Danvers, MA, 2013.

27. Thomas ME. The Alaska Native Claims Settlement Act: conflict and controversy. Polar Record 1986;23:27-36.

28. Na Iwi O Na Kupuna O Mokapu v. Dalton, 894 F. Supp. 1397 (D. Haw. 1995).

29. Tsosie R. Cultural challenges to biotechnology: Native American genetic resources and the concept of cultural harm. J Law Med Ethics 2007;35:396-411.

30. Tallbear K. Genetics, culture and identity in Indian country. Paper presented at Seventh International Congress of Ethnobiology, October $2000 \mathrm{http}: / / \mathrm{www}$. iiirm.org/publications/Articles\%20Reports\%20Papers/Genetics\%20and\%20 Biotechnology/ISEPaper.pdf. Accessed 2 April 2014.

31. Singeo L. The patentability of the Native Hawaiian genome. Am J Law Med 2007;33:119-139.

32. Inter Tribal Council of Arizona website. www.itcaonline.com. Accessed 2 April 2014.

33. Hiratsuka V, Brown J, Dillard D. Views of biobanking research among Alaska native people: the role of community context. Prog Community Health Partnersh 2012;6:131-139.

34. The International Warfarin Pharmacogenetics Consortium. Estimation of the warfarin dose with clinical and pharmacogenetic data. N Engl J Med 2009;360:753-764.

35. Executive Order No. 13175 on Consultation and Coordination with Indian Tribal Governments. The White House website. Published 9 November 2000. http://www.gpo.gov/fdsys/pkg/FR-2000-11-09/pdf/00-29003.pdf. Accessed 2 April 2014

36. UN Declaration on the Rights of Indigenous Peoples, Art 19; Art 32. http:// www.un.org/esa/socdev/unpfii/documents/DRIPS_en.pdf.

37. Population Architecture using Genomics and Epidemiology (PAGE): Causal Variants Across the Life Course (CALiCo): Strong Heart Study (SHS) and Strong Heart Family Study (SHFS). http://www.ncbi.nlm.nih.gov/projects/gap/cgi-bin/ study.cgi?study_id=phs000580.v1.p1. Accessed 2 April 2014.

38. Research that benefits Native people: a guide for tribal leaders. National Congress of American Indians Policy Research Center website. http://www. ncaiprc.org/research-curriculum-guide. Accessed 2 April 2014.

39. PRC tribal research regulation kit. National Congress of American Indians Policy Research Center website. http://www.ncaiprc.org/research-regulation. Accessed 2 April 2014.

40. American Indian and Alaska Native Genetics Resource Center. National Congress of American Indians Policy Research Center website. Published September 2009. http://genetics.ncai.org. Accessed 2 April 2014.

41. Taniguchi NK, Taualii M, Maddock J. A comparative analysis of indigenous research guidelines to inform genomic research in indigenous communities. Int Indigenous Pol J 2012;3. http://ir.lib.uwo.ca/iipj/vol3/iss1/6. Accessed April 06, 2014.

42. Rodriguez LL, Brooks LD, Greenberg JH, Green ED. Research ethics. The complexities of genomic identifiability. Science 2013;339:275-276. 